\title{
Influência da alimentação escalonada na biodegradação de corante têxtil por fungos imobilizados em reator em bateladas sequenciais
}

\section{Influence of stepped feed in Biodegradation of Textile Dye by immobilized fungi in Batch Sequential Reactors}

Data de entrada: $12 / 05 / 2017$

Data de aprovação: $13 / 12 / 2017$

Gustavo Evangelista dos Santos*/Andreza Dnarla Oliveira Santos/Amanda Moraes Araújo/ Carlos Ronald Pessoa Wanderley/Glória Marinho/Kelly Rodrigues

DOI: $10.4322 /$ dae.2019.005

\section{Resumo}

O presente trabalho teve como objetivo avaliar a viabilidade do tratamento fúngico em reatores operados em regime de batelada escalonada durante duas etapas. Na primeira, foram operados dois reatores, um contendo o fungo Aspergillus niger, no qual foi obtida remoção de corante de 34,5\%, e de DQQ Bruta e Solúvel de $46 \%$ e $57 \%$, respectivamente. No segundo reator, utilizou-se o fungo Phanerochaete chrysosporium, tendo sido a remoção média de corante de $32 \%$ e a remoção de DQ O Bruta eSolúvel de $55 \%$ e $69 \%$, respectivamente. Ao final dessa etapa, um novo reator foi operado em regime convencional utilizando Phanerochaete chrysosporium onde os dados foram superiores àqueles observados na batelada escalonada. A remoção de corantefoide 75\%, ea remoção de DQQ B Brutafoide $60 \%$. Palavras-chave: Aspergillus niger. Phanerochaete chrysosporium. Efluente. Eficiência.

\section{Abstract}

The present work aimed to evaluate the viability of the fungic treatment in reactors operated in batch regime staggered during two stages. In the first one were operated two reactors, one containing the fungus Aspergillus niger where the dye removal was 34,5\% and the removal of crude and soluble COD was $46 \%$ and $57 \%$, respectively. In the second reactor the fungus Phanerochaete chrysosporium was used, being the average dye removal of $32 \%$ and the removal of crude and soluble COD of 55\% and $69 \%$ respectively. At the end of this stage, a new reactor was operated in a conventional regime using Phanerochaete chrysosporium, where the data were higher than those observed in the stepped batch. The dye removal was $75 \%$ and the removal of crude COD was $60 \%$. Keywords: Aspergillus niger. Phanerochaete chrysosporium. Effluent. Efficiency.

Gustavo Evangelista dos Santos - Discente de Graduação em Engenharia Ambiental e Sanitária do Instituto Federal de Educação, Ciência e Tecnologia do Ceará (IFCE). Bolsista de Iniciação Científica do IFCE.

Andreza Dnarla Oliveira Santos - Tecnóloga em Gestão Ambiental pelo Instituto Federal de Educação, Ciência e Tecnologia do Ceará (IFCE). Mestra em Tecnologia e Gestão Ambiental pelo Programa de pós-graduação em Tecnologia e Gestão Ambiental do IFCE. Discente de graduação em Engenharia Ambiental e Sanitária do IFCE.

Amanda Moraes Araújo - Discente de Graduação em Engenharia Ambiental e Sanitária do Instituto Federal de Educação, Ciência e Tecnologia do Ceará (IFCE). Bolsista de Iniciação Científica do IFCE.

Carlos Ronald Pessoa Wanderley - Engenheiro Civil pela Universidade Federal do Ceará (UFC). Mestre em Saneamento Ambiental pela Universidade Federal do Ceará (UFC). Professor do Departamento do Eixo da Química e Meio Ambiente (IFCE).

Glória Marinho - Farmacêutica pela Universidade Federal do Ceará (UFC). Doutora em Hidráulica e Saneamento pela Escola de Engenharia de São Carlos (EESC - USP). Professora do Departamento de Química e Meio Ambiente e do Programa de pós-graduação em Tecnologia e Gestão Ambiental do IFCE.

Kelly Rodrigues - Engenheira Civil pela Universidade Federal do Maranhão (UEMA). Doutora em Hidráulica e Saneamento pela Escola de Engenharia de São Carlos (EESC - USP). Professora do Departamento de Química e Meio Ambiente e do Programa de pós-graduação em Tecnologia e Gestão Ambiental do IFCE.

"Endereço para correspondência: Rua Olga Barroso, 372 - Mucuripe - Fortaleza - Ceará - CEP: 60175390. Telefones: (85) 3109-3834 / (85) 98632-1139. E-mail: gustavosantos.evagmail.com. 


\section{INTRODUÇÃO}

O vestuário tem sido considerado a segunda maior necessidade da humanidade após a alimentação. Esse importante setor da indústria, porém, requer volumes elevados de água, principalmente para as etapas de tingimento e acabamento, conforme Ribeiro et al. (2014).

Como consequência dessa demanda elevada de água, de acordo com Kunz et al. (2002), o setor têxtil acaba gerando também volume grande de efluentes, os quais, se não forem corretamente tratados, podem causar problemas de contaminação ambiental.

Segundo os estudos de Koprivanac e Kusic (2008), a produção mundial de pigmentos e corantes sintéticos supera a marca de $7 \times 10^{5}$ toneladas por ano e, de acordo com Hessel et al (2007), e de acordo com Guaratini e Zanoni (2000), 1,2 toneladas por dia desses compostos são liberados no meio ambiente.

Cada tipo de fibra requer uma classe específica de corante, e para Leite et al. (2013), isso é uma grande barreira, sendo necessária a otimização de processos visando a um menor consumo de energia e menor índice de impactos ambientais.

O tratamento destes efluentes se faz necessário, tanto pela presença de corantes como de compostos auxiliares. Devido a sua característica recalcitrante, os corantes não são facilmente degradados em técnicas convencionais de degradação, tendo fungos e bactérias como os principais decompositores encontrados para remediar esses compostos por meio do tratamento biológico dos efluentes (ERDUNLU et al., 2012; ALMEIDA et al., 2012).

Os fungos possuem grande capacidade de degradar poluentes resistentes, por meio da ação de enzimas por eles produzidas, as quais são capazes de despolimerizar grande variedade de compostos como os corantes têxteis e outros poluentes persistentes (DULLIUS, 2004).

Dentro desse cenário, a busca por tecnologias eficientes e menos onerosas é incessante. A tecnologia fúngica aplicada ao tratamento de águas residuárias têxtil vem sendo estudada, obtendo-se resultados interessantes. Contudo, há necessidade urgente de otimizar a tecnologia, buscando alcançar percentuais maiores de remoção de corantes e de subprodutos, o que pode ser conseguido com o esquema operacional do reator. Assim, neste trabalho foi feito o estudo do tratamento de efluente têxtil por fungos imobilizados em reatores em batelada que foram alimentados de forma convencional e escalonada, esta última com a adição inicial de água residuária - começo de ciclo - e alimentação intermediária com novo aporte de água residuária, ao final do ciclo.

\section{MATERIAIS E MÉTODOS}

\subsection{Cultivo dos fungos Aspergillus niger e Phanerochaete chrysosporium}

Os fungos Aspergillus niger e Phanerochaete chrysosporium foram replicados em placas de Petri previamente esterilizadas contendo meio Potato Dextrose Agar (PDA). As placas permaneceram a $28^{\circ} \mathrm{C}$, por sete dias, para o crescimento dos esporos em toda sua superfície. Para a inoculação do fungo no reator, foi utilizado um fura rolhas estéril de $8 \mathrm{~mm}$ de diâmetro, segundo metodologia de Ottoni (2012). Desta forma, foram retirados discos da área periférica da colônia crescida em placa e acrescidos ao reator, numa proporção de 5 discos para cada $250 \mathrm{~mL}$ de meio basal.

\subsection{Imobilização da biomassa}

O procedimento de imobilização dos fungos no material suporte ocorreu com a imobilização do inóculo em espuma de poliuretano cortada em cubo de $1 \mathrm{~cm}$ de aresta. Primeiramente pesaram- 
-se aproximadamente $15 \mathrm{~g}$ de espumas, que foram divididas em três redes de polietileno e colocadas dentro do reator.

0 meio de crescimento para ambos os gêneros fúngicos consistia de $1 \mathrm{~g} \cdot \mathrm{L}^{-1}$ de glicose e meio sintético $\left(\left(\mathrm{NH}_{4}\right)_{2} \mathrm{SO}_{4} 0,5 \mathrm{~g} / \mathrm{L}, \mathrm{NaNO}_{3} 0,25 \mathrm{~g} / \mathrm{L}\right.$, $\mathrm{KH}_{2} \mathrm{PO}_{4} 0,20 \mathrm{~g} / \mathrm{L}, \mathrm{MgSO}_{4} 0,25 \mathrm{~g} / \mathrm{L}, \mathrm{CaCl}_{2} \cdot 2 \mathrm{H}_{2} \mathrm{O}$ $0,01 \mathrm{~g} / \mathrm{L}, \mathrm{CuSO}_{4} .7 \mathrm{H}_{2} \mathrm{O} 0,08 \mathrm{~g} / \mathrm{L}, \mathrm{H}_{2} \mathrm{MoO}_{4} 0,05 \mathrm{~g} / \mathrm{L}$, $\mathrm{MnSO}_{4} \cdot 5 \mathrm{H}_{2} \mathrm{O} 0,05 \mathrm{~g} / \mathrm{L}, \mathrm{Fe}_{2}\left(\mathrm{SO}_{4}\right)_{3} 0,05 \mathrm{~g} / \mathrm{L}, \mathrm{ZnSO}_{4}$ $0,04 \mathrm{~g} / \mathrm{L})$.

Os reatores passaram cerca de 15 dias recebendo a alimentação adequada para que se obtivesse um melhor crescimento da biomassa dentro do reator sendo que o meio sintético era trocado a cada 72 horas. Após esse período, o reator passou a receber o poluente a ser tratado.

Os reatores da etapa 1 foram operados por $8 \mathrm{ci}-$ clos, em regime de batelada escalonada, cada ciclo com tempo reacional (TR) de $48 \mathrm{~h}$, de modo que no início de cada ciclo a água residuária sintética era renovada.

\subsection{Montagem do reator em batelada sequencial e alimentação escalonada}

O reator em bateladas sequenciais era cilíndrico, em vidro, e possuía volume total de $5 \mathrm{~L}$, sendo o volume reacional (TR) de $4 \mathrm{~L}$, além de vedação na parte superior que consistia de tampa plástica rosqueável (Figura 1), com passagem para mangueira - com diâmetro interno de $4 \mathrm{~mm}$ - para fornecimento de ar, o qual foi provido no meio por uso de mini-compressor de ar com vazão de $250 \mathrm{~L} / \mathrm{h}$. 0 reator foi envolto por saco preto de polietileno para evitar possível fotodegradação do corante.

O preparo da água residuária para o gênero Phanerochaete chrysosporium foi realizado com água de torneira acrescida do corante Índigo Carmim (20 $\left.\mathrm{mg} \cdot \mathrm{L}^{-1}\right)$, glicose (1 $\left.\mathrm{g} \cdot \mathrm{L}^{-1}\right)$, Solução de Micronutrientes $\left(10 \mathrm{~mL} \cdot \mathrm{L}^{-1}\right)(\mathrm{g} / \mathrm{L}): \mathrm{MgSO}_{4} \cdot 7 \mathrm{H}_{2} \mathrm{O}(3,0), \mathrm{NaCl}(1,0)$,
$\mathrm{MnSO}_{4} \cdot \mathrm{H}_{2} \mathrm{O}(0,5), \mathrm{FeSO}_{4} \cdot 7 \mathrm{H}_{2} \mathrm{O}(0,1), \mathrm{ZnSO}_{4} \cdot \mathrm{H}_{2} \mathrm{O}$ $(0,1), \mathrm{CoCl}_{2} \cdot 6 \mathrm{H}_{2} \mathrm{O}(0,1), \mathrm{CaCl}_{2} \cdot 2 \mathrm{H}_{2} \mathrm{O}(0,082), \mathrm{H}_{3} \mathrm{BO}_{3}$ $\left.(0,01), \mathrm{CuSO}_{4} \cdot 5 \mathrm{H}_{2} \mathrm{O}(0,01)\right)$ e Macronutrientes $(\mathrm{g} / \mathrm{L})$ : $\mathrm{KH}_{2} \mathrm{PO}_{4}(0,2), \mathrm{MgSO}_{4} \cdot 7 \mathrm{H}_{2} \mathrm{O}(0,5), \mathrm{CaCl}_{2} \cdot 2 \mathrm{H}_{2} \mathrm{O}(0,1)$, $\left(\mathrm{NH}_{4}\right) 2 \mathrm{SO}_{4}(0,2)$ e antibiótico MegacilinSuperPlus $(0,1 \mathrm{~g} \cdot \mathrm{L}-1)$.

Para o gênero Aspergillus niger utilizou-se solução de Vishniac (1 mL.L-1) (g/L): EDTA (10,0), $\mathrm{ZnSO}_{4}$. $7 \mathrm{H}_{2} \mathrm{O}(4,4), \mathrm{MnCl}_{2} \cdot 4 \mathrm{H}_{2} \mathrm{O}(1,0), \mathrm{CoCl}_{2} \cdot 6 \mathrm{H}_{2} \mathrm{O}(0,32)$, $\left(\mathrm{NH}_{4}\right) 6 \mathrm{Mo}_{24} \cdot 4 \mathrm{H}_{2} \mathrm{O}(0,22), \mathrm{CaCl}_{2} \cdot 2 \mathrm{H}_{2} \mathrm{O}(1,47)$, $\mathrm{FeSO}_{4} \cdot 7 \mathrm{H}_{2} \mathrm{O}(1,0)$ e antibiótico MegacilinSuperPlus $\left(0,1 \mathrm{~g} \cdot \mathrm{L}^{-1}\right)$, não se utilizou macronutrientes.

Os reatores da etapa 1 foram operados em regime de batelada escalonada, de forma que inicialmente eram adicionados metade do volume total do efluente a ser tratado e após 24 horas adicionava-se o restante do volume com concentração de glicose em $1 \mathrm{~g} \cdot \mathrm{L}^{-1}$ para o gênero Aspergillus niger e 0,25 g. $\mathrm{L}^{-1}$ para o gênero Phanerochaete chrysosporium.

As análises eram realizadas na entrada e após 24 horas uma alíquota do efluente era retirada para análise. Analisava-se a água residuária sintética que entrava após 24 horas, e também após a mistura da água, completando o volume total de 4L.

\subsection{Operação do reator em batelada sequencial convencional}

$\mathrm{Na}$ etapa 2 da pesquisa, um reator foi operado em regime de bateladas sequenciais convencionais, de modo que a cada 24 horas uma nova concentração de $0,25 \mathrm{~g} . \mathrm{L}^{-1}$ de glicose era adicionada ao reator.

As análises eram realizadas na entrada, e após 24 horas uma alíquota do efluente era retirada para análise. 


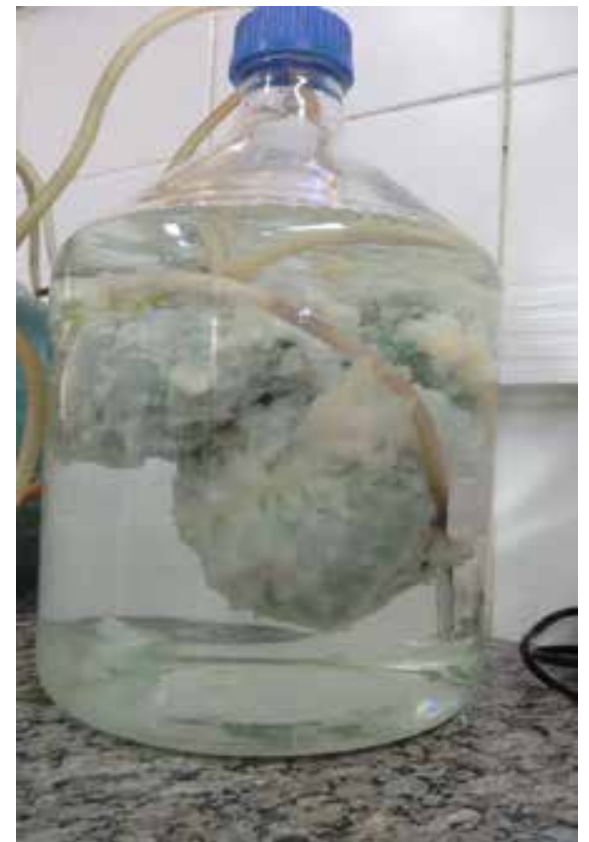

Figura 1 - Reator com biomassa fúngica imobilizada em espuma de poliuretano

O volume amostral retirado em cada ciclo para a realização das análises foi apenas $10 \%$ do volume útil do reator por ciclo estudado, realizando-se determinações no afluente e efluente das variáveis: $\mathrm{pH}$; matéria orgânica bruta e solúvel, com cossubstrato, em termos de DQO e concentração de corante. As variáveis foram obtidas utilizando os métodos descritos por APHA (2005), exceto corante, que ocorreu segundo método descrito por Rodrigues et al. (2011), com uso de espectrofotômetro UV VIS e leitura de absorbância a 610 $\mathrm{nm}$ (cor real).

\section{RESULTADOS E DISCUSSÃO}

\subsection{Etapa 1}

Nas Tabelas 1 e 2 são mostradas, respectivamente, as características da água residuária antes e após o tratamento biológico no reator com fungos.
Tabela 1: Características da água residuária sintética que foi utilizada na alimentação do reator

\begin{tabular}{|c|c|c|}
\hline \multirow{2}{*}{ Variável } & \multicolumn{2}{|c|}{ Concentração Média / Desvio Padrão } \\
\cline { 2 - 3 } & Aspergillu sniger & $\begin{array}{c}\text { Phanerochaete } \\
\text { chrysosporium }\end{array}$ \\
\hline CORANTE & $20,07 \pm 0,10$ & $20,30 \pm 0,19$ \\
\hline DQO BRUTA & $1259,78 \pm 289,35$ & $1028,57 \pm 257,71$ \\
\hline DQO SOLÚVEL & $1118,00 \pm 414,45$ & $1025,08 \pm 263,78$ \\
\hline pH & $5,04 \pm 0,05$ & $5,03 \pm 0,04$ \\
\hline
\end{tabular}

Tabela 2: Características da água residuária que saía do reator em 48 horas

\begin{tabular}{|c|c|c|}
\hline \multirow{2}{*}{ Variável } & \multicolumn{2}{|c|}{ Concentração Média / Desvio Padrão } \\
\cline { 2 - 3 } & Aspergillu sniger & $\begin{array}{c}\text { Phanerochaete } \\
\text { chrysosporium }\end{array}$ \\
\hline CORANTE & $13,13 \pm 3,16$ & $13,77 \pm 3,19$ \\
\hline DQO BRUTA & $700,64 \pm 393,35$ & $443,22 \pm 158,25$ \\
\hline DQO SOLÚVEL & $473,75 \pm 321,95$ & $316,73 \pm 155,33$ \\
\hline pH & $5,04 \pm 1,88$ & $2,94 \pm 0,47$ \\
\hline
\end{tabular}

Durante a operação do reator contendo inóculo do fungo Aspergillus niger, as análises de remoção de corante (Figura 2) apresentaram remoção média de $34,5 \%$, com máxima de $70 \%$ no ciclo 1 e mínima de $21 \%$ no ciclo 8 . A concentração média na entrada foi de $20 \mathrm{mg} / \mathrm{L}^{-1}$, como observado na Tabela 1, enquanto na saída a concentração média foi de $14 \mathrm{mg} / \mathrm{L}^{-1}$, com máxima de $15,9 \mathrm{mg} / \mathrm{L}^{-1}$ no ciclo 8 e mínima de 6 $\mathrm{mg} / \mathrm{L}^{-1}$ no ciclo 1.

Para a matéria orgânica em termos de DQQO bruta e solúvel, o reator em batelada escalonada apresentou remoção superior àquelas observadas para corante (Figura 3 e 4). A DQO Bruta foi removida com percentual superior a $40 \%$, em todos os ciclos, com exceção do ciclo 6 , onde não houve remoção. A remoção média foi $46 \%$, tendo o ciclo 2 apresentado remoção de $75 \%$, sendo a máxima remoção observada para DQO Bruta. Para a DQO Solúvel, a remoção média foi de $57 \%$ com máxima de $75 \%$, no ciclo 1 , e mínima de $20 \%$, no ciclo 6 . 


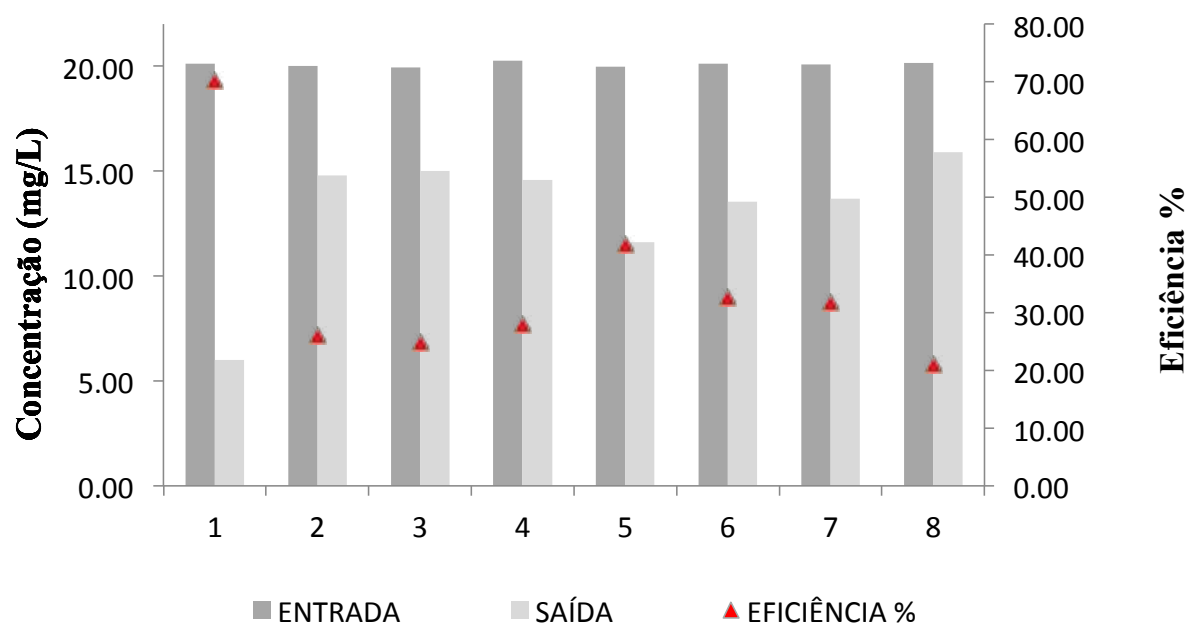

Figura 2 - Eficiência de Remoção de Corante em reator com inóculo de Aspergillus niger (Etapa 1)

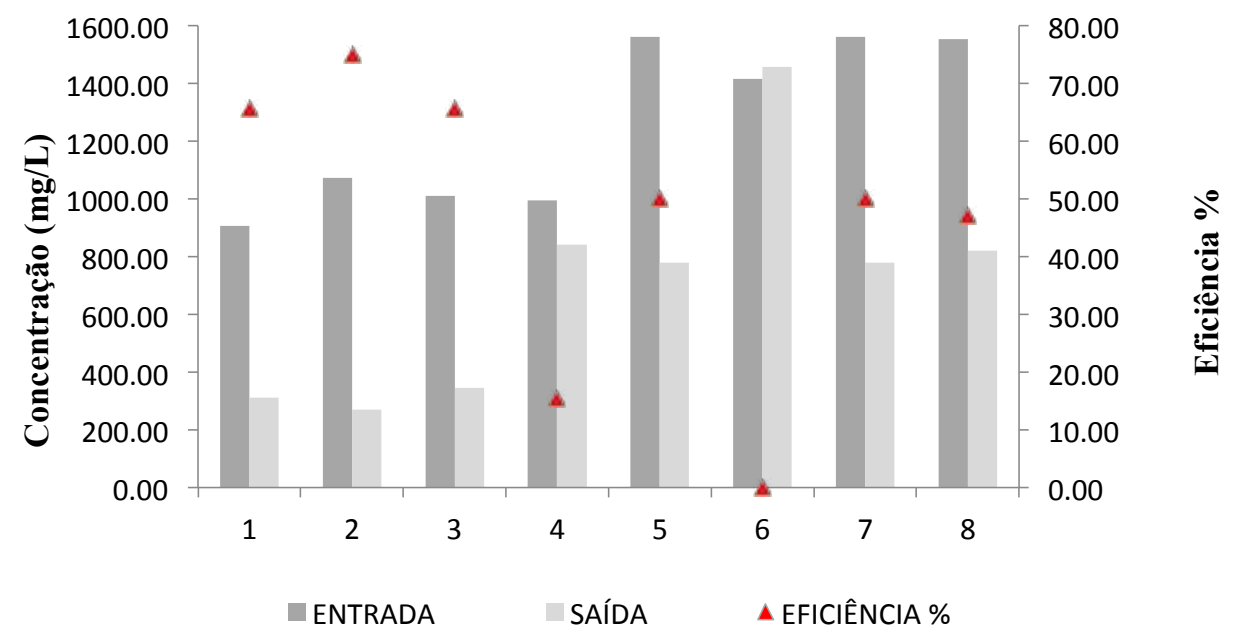

Figura 3 - Eficiência de Remoção de DQO Bruta em reator com inóculo de Aspergillus niger (Etapa 1).

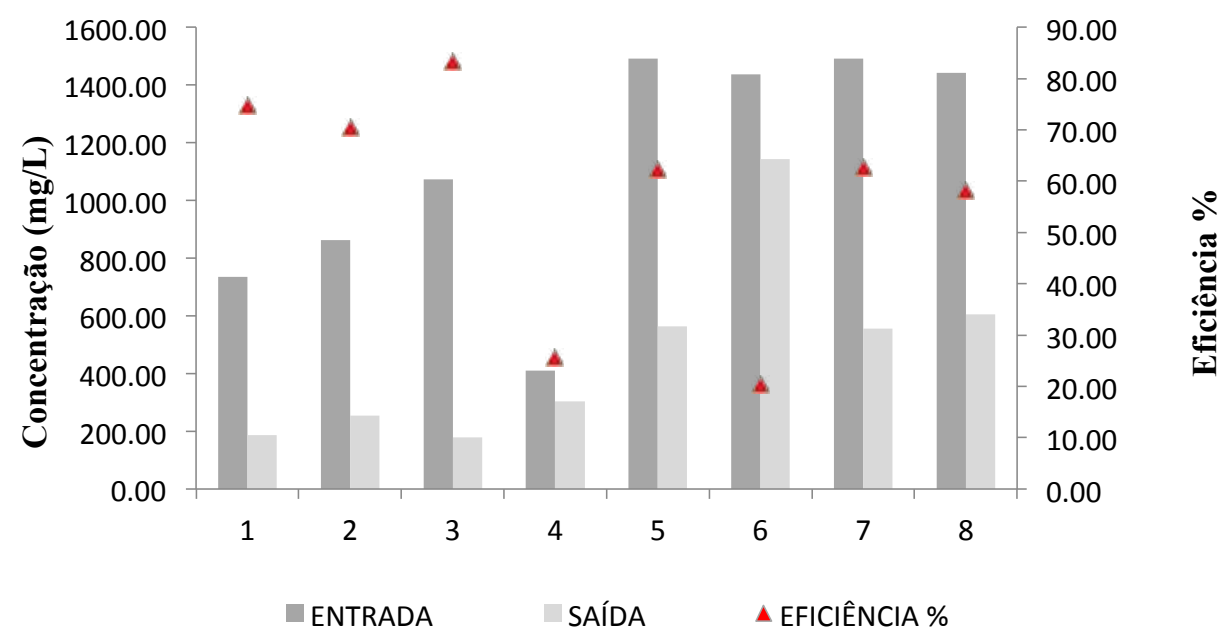

Figura 4 - Eficiência de Remoção de DQQO Solúvel em reator com inóculo de Aspergillus niger (Etapa 1). 
Na saída do reator, a maioria dos valores de $\mathrm{pH}$ se mantiveram na faixa ácida (Figura 5), com exceção dos ciclos 7 e 8 que ficaram em torno de 7 . O menor valor de pH observado ocorreu no ciclo 5, com valor de 2,72. A média da saída foi de 5,04

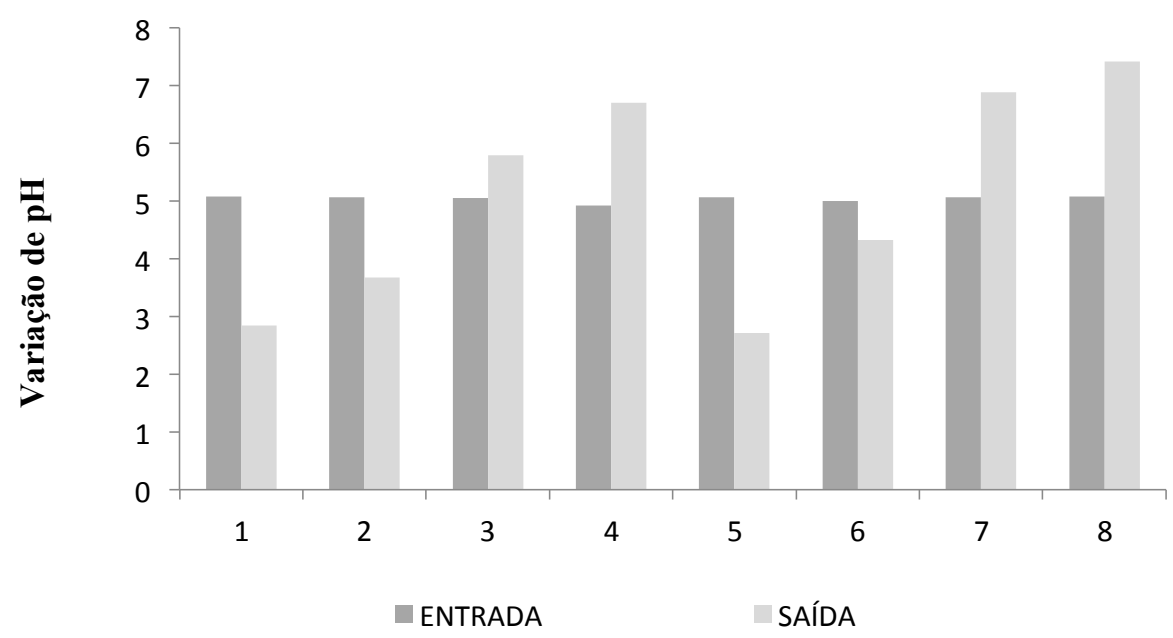

Figura 5 - Variação de pH em reator com inóculo de Aspergillus niger (Etapa 1)

O reator contendo inóculo de Phanerochaete chrysosporium apresentou remoção média de corante de $32 \%$, com mínima de $13 \%$, no ciclo 8 , e máxima de $62,7 \%$, no ciclo 1 (Figura 6). A concentração média na entrada era de $20,30 \mathrm{mg} / \mathrm{L}^{-1}$, enquanto na saída a concentração média foi $13,77 \mathrm{mg} / \mathrm{L}^{-1} \mathrm{com}$ máxima de $17,4 \mathrm{mg} / \mathrm{L}^{-1}$ no ciclo 8 e mínima de 7,66 mg/L-1 no ciclo 1 .

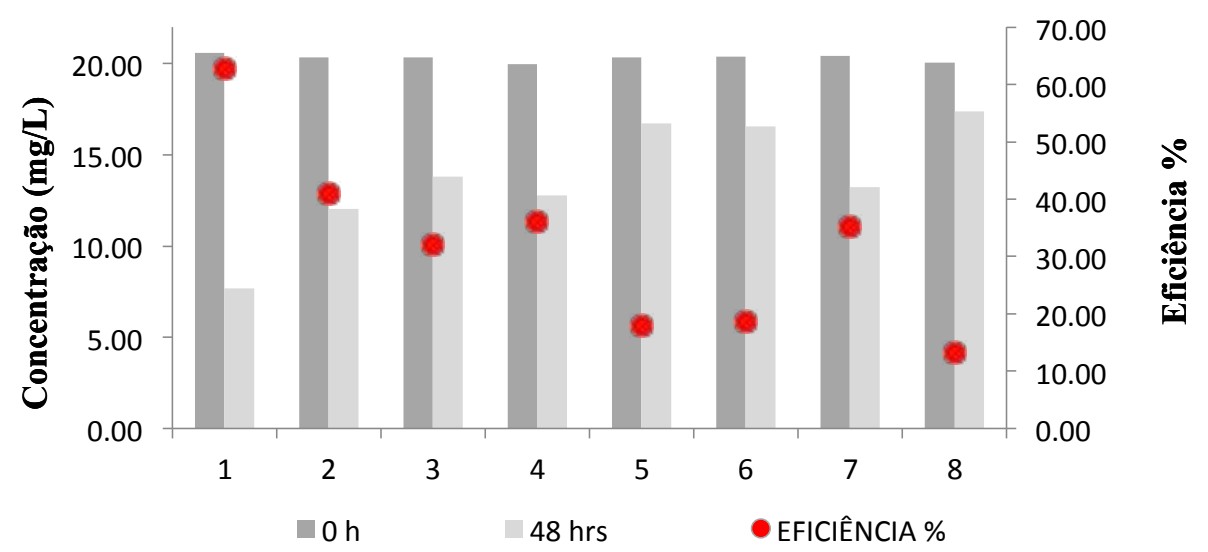

Figura 6 - Eficiência de Remoção de Corante em reator com inóculo de Phanerochaete chrysosporium (Etapa 1).

Para a DQQ as remoções médias foram de $55 \%$ e $69 \%$ para DQO bruta e solúvel respectivamente (Figuras 7 e 8). A eficiência máxima para DQQ Bruta ocorreu no ciclo 1, cujo valor foi de $67 \%$, enquanto a mínima foi de $25 \%$ no ciclo 5. Para DQO solúvel, a eficiência máxima ocorreu no ciclo 3, cujo valor foi 84,5\%, e a mínima apresentou 49\% (Ciclo 5). 


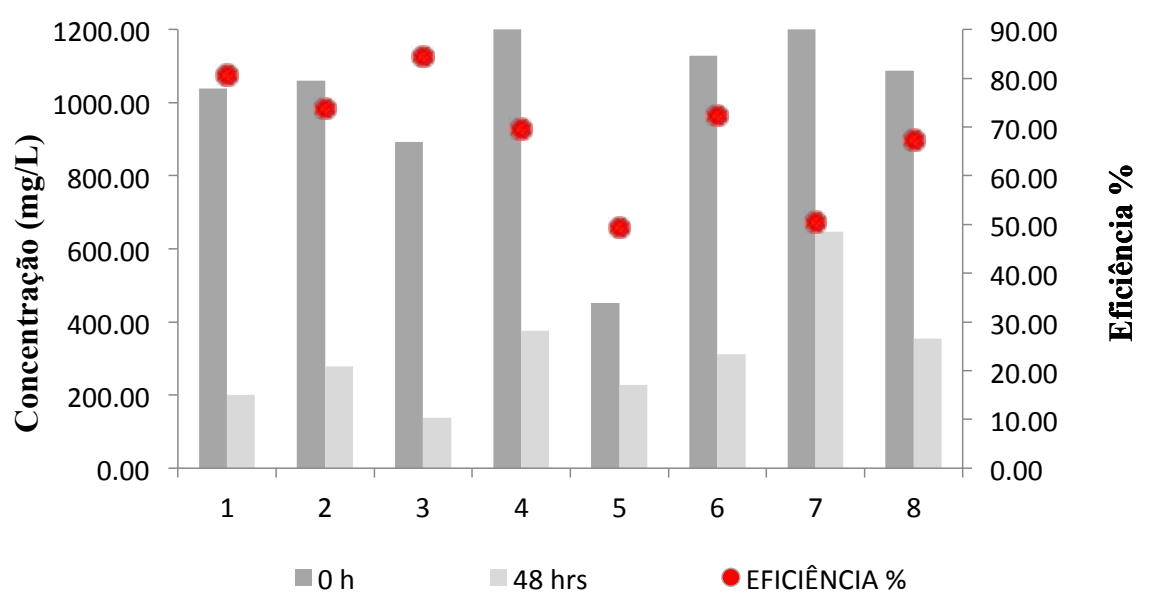

Figura 7 - Eficiência de Remoção de DQQ Bruta em reator com inóculo de Phanerochaete chrysosporium (Etapa 1).

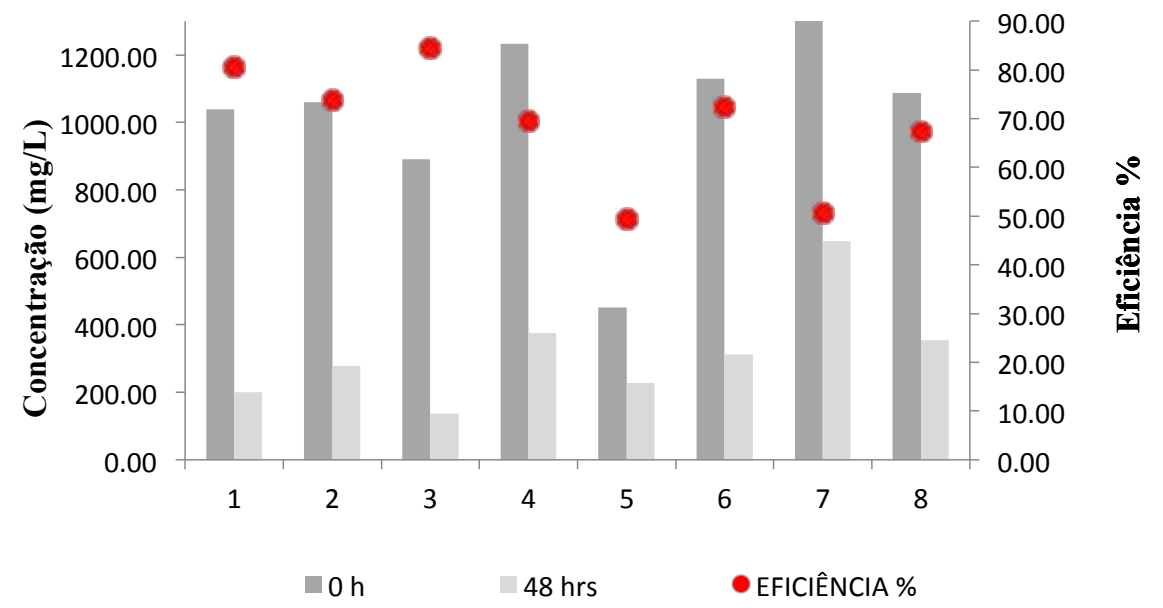

Figura 8 - Eficiência de Remoção de DQQ Solúvel em reator com inóculo de Phanerochaete chrysosporium (Etapa 1).

Na saída do reator, os valores de pH se mantiveram na faixa ácida, em torno de 2,94, com máxima de 3,70 no ciclo 7 e mínima de 2,19 no ciclo 3 (Figura 9).

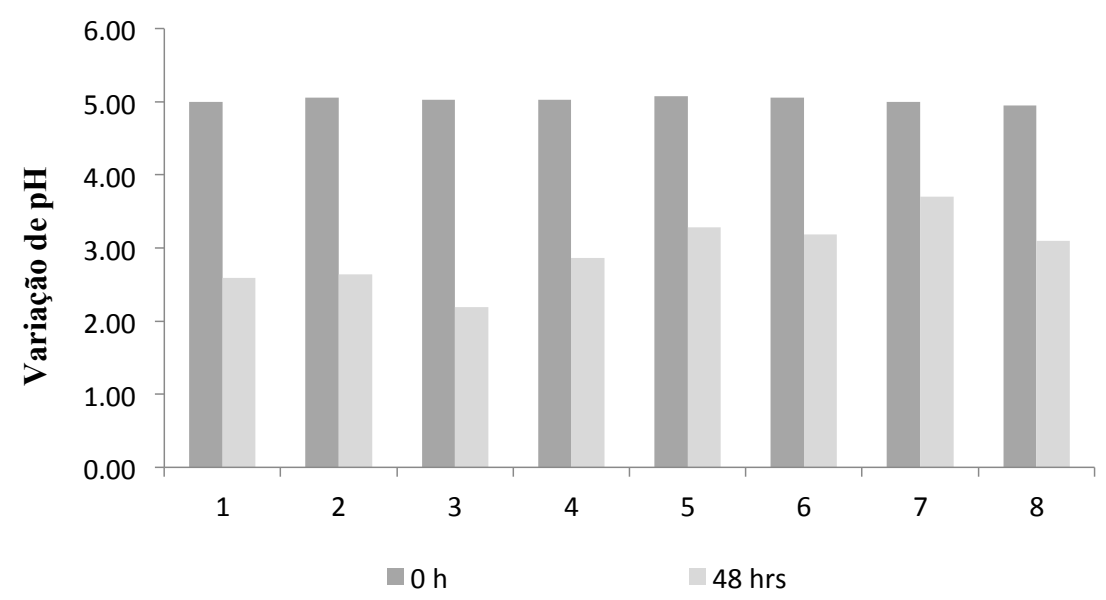

Figura 9 -Variação de pH em reator com inóculo de Phanerochaete chrysosporium (Etapa 1). 
Na etapa 1 ocorreram melhores remoções de DQQ em detrimento das remoções relativas ao corante, podendo isso ser justificado pelo fato de que o fungo provavelmente consumiu a glicose como fonte primária de carbono em detrimento do corante. Ainda assim, é importante mencionar que todos os ciclos apresentaram em comum o acúmulo de subprodutos aromáticos que continham anel benzênico. Isso foi verificado pelas varreduras, nos comprimentos de onda de $200 \mathrm{~nm}$ à 1000 $\mathrm{nm}$, realizadas no afluente e efluente do reator, primeira e segunda etapa, ao longo da suas operações, nas Figuras 10 a 13, estão representadas as varreduras realizadas nos dois melhores ciclos em relação à remoção de corante, observadas na etapa 1 para ambos os reatores.

As varreduras realizadas no início e no final de cada ciclo, para ambos os reatores, mostraram a diminuição da banda em $610 \mathrm{~nm}$, relativa ao grupo cromóforo do corante, ainda que muito pequena.

Não houve mineralização completa do corante devido ao indicativo da formação de subprodutos decorrentes da quebra da molécula de corante, tais como o benzeno. Além disso, foi observada a presença de cor no efluente do reator, endossando a mineralização incompleta do corante Índigo. Segundo Bertazzoli e Pelegrini (2002), a presença de concentrações pequenas de corante em água é suficiente para configurar em cor elevada, uma vez que devido à sua natureza os corantes são detectáveis pelo olho humano mesmo em concentrações de $1 \mathrm{mg} / \mathrm{L}^{-1}$, sendo os corantes reativos detectáveis em concentrações ainda menores.

Silva et al (2015) realizaram o estudo da degradação de corante Índigo Carmim in natura e efetuaram as varreduras do afluente e efluente, constatando a presença de compostos aromáticos, como o benzeno, tendo sido avaliada a presença deste composto no comprimento de onda de 205 nm e outros compostos aromáticos no comprimento de $265 \mathrm{~nm}$, sendo que neste último os autores observaram decréscimo da banda no efluente em relação ao afluente.

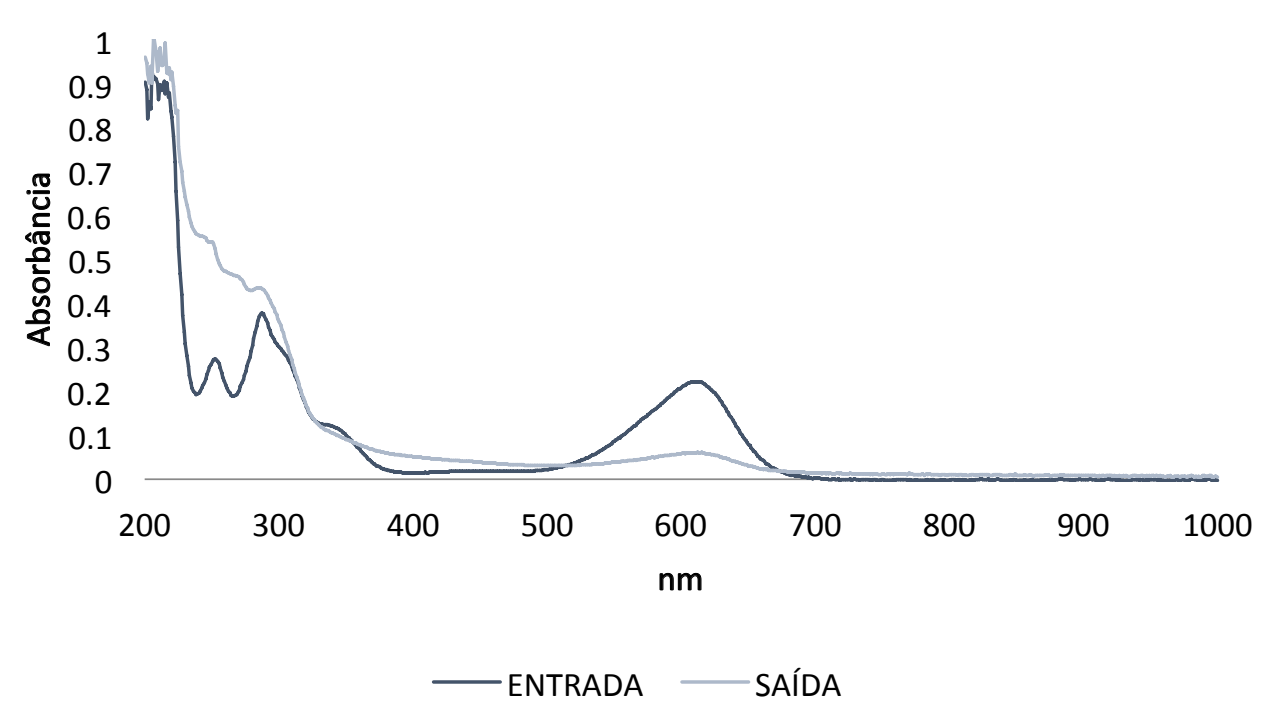

Figura 10 -Varredura realizada no afluente e efluente do reator com Aspergillus niger (Ciclo 1). 


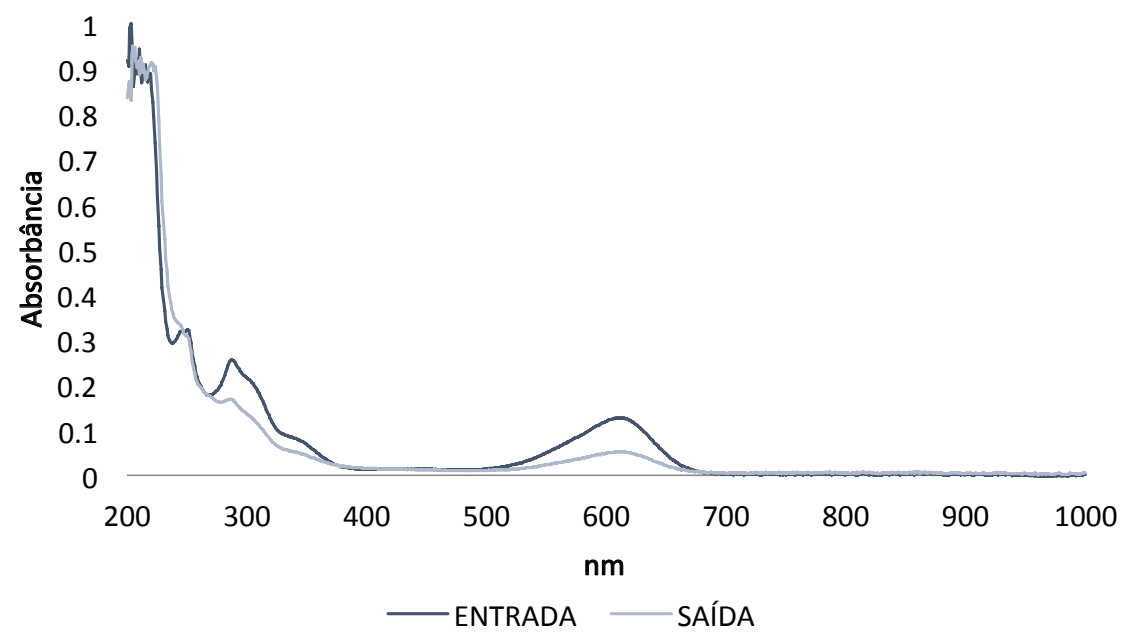

Figura 11 -Varredura realizada no afluente e efluente do reator com Aspergillus niger (Ciclo 5).

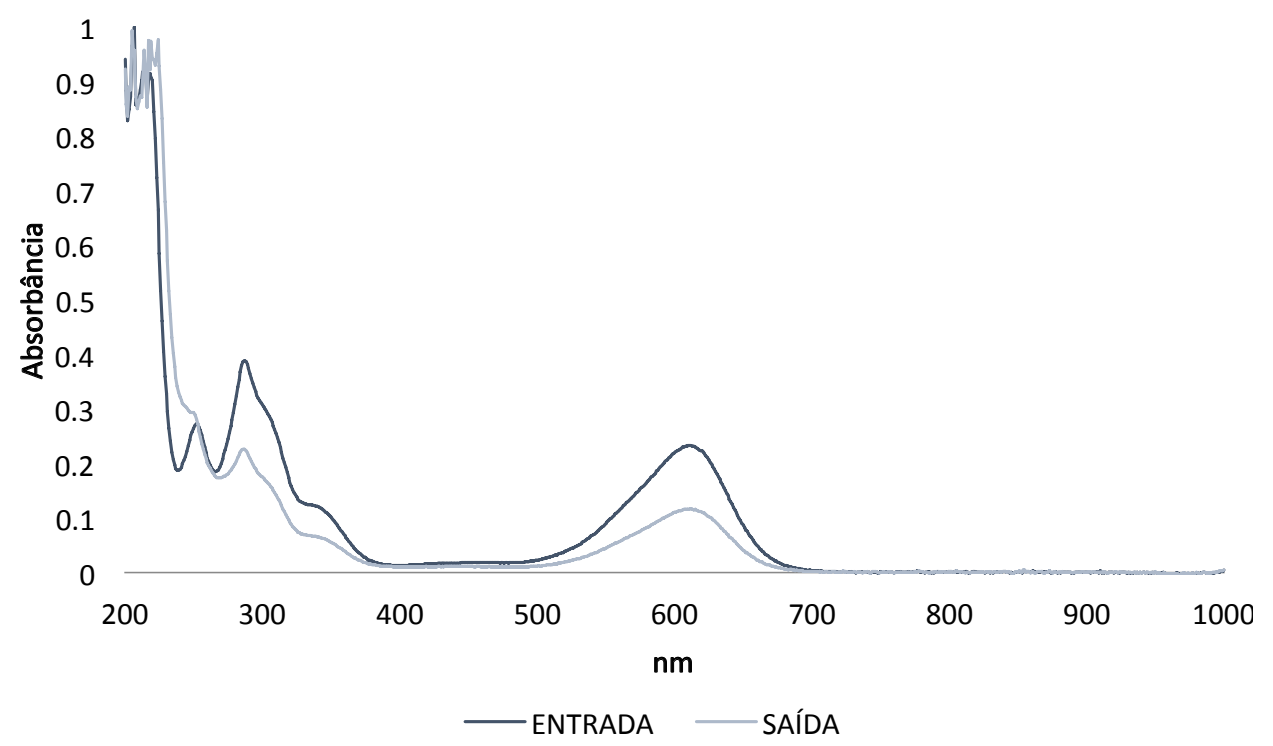

Figura 12 -Varredura realizada no afluente e efluente do reator com Phanerochaete chrysosporium (Ciclo 1).

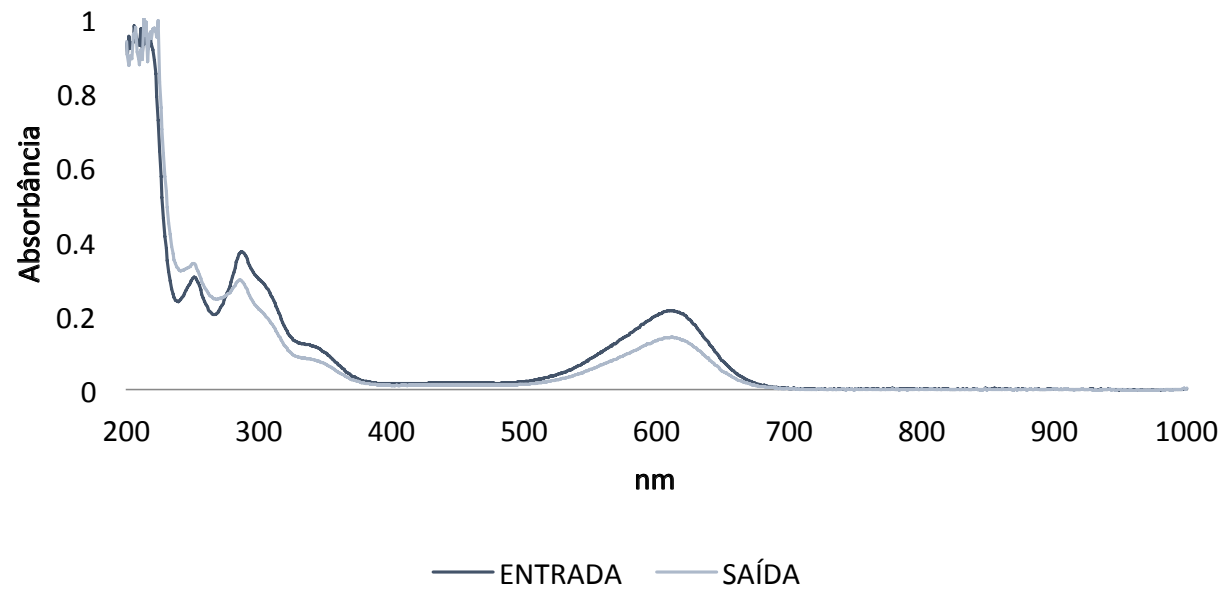

Figura 13 -Varredura realizada no afluente e efluente do reator com Phanerochaete chrysosporium (Ciclo 2). 
De acordo com Carvalho (2014), o benzeno é um tipo de hidrocarboneto monoaromático de reconhecida toxicidade e possui o mais baixo padrão de qualidade de água cujo valor é 10 microgramas por litro.

A Resolução Conama 430, de 2011, estabelece o valor de 1,2 mg/L de benzeno permissível para lançamento de efluente em corpos hídricos. Esse composto possui difícil degradabilidade, e pode causar efeitos deletérios em ecossistemas contaminados, havendo necessidade de remediar este composto.

No presente estudo, as varreduras realizadas na etapa 1 com o reator contendo inóculo de Aspergillus niger mostraram diminuição na banda de $205 \mathrm{~nm}$ em todos os ciclos, com exceção do ciclo 1. Para o reator contendo inóculo de Phanerochaete chrysosporium, houve remoção apenas nos ciclos 4 e 8.

Não foram encontrados trabalhos relacionados com tratamento de efluente têxtil em regime de batelada escalonada, porém Costa (2005) estudou o desempenho de um reator de lodo ativado operado em batelada sequencial com enchimento escalonado no tratamento de esgoto sanitário doméstico, em que as cargas de DQQ variaram de 0,33 a 2,14 kg DQO/ $\mathrm{m}^{3}$.dia e o tempo de retenção variou entre 4 e 12 horas. Ao longo dos 10 meses de operação, o tratamento apresentou eficiência média de $78 \%$.

Com base nos resultados obtidos, não houve degradação total de corante índigo carmim utilizando o processo de alimentação escalonada, fazendo com que o efluente final ainda apresentasse cor, além de considerável presença de matéria orgânica. Portanto tornando-o inviável para o lançamento em um corpo hídrico de acordo com a legislação.

Um reator operado em regime de batelada convencional foi montado a fim de realmente atestar a eficiência da utilização dos fungos para o tratamento de efluente têxtil. Assim, a espécie fúngica Phanerochate chrysosporium foi inoculada no reator, e durante a operação, a cada 24 horas eram adicionados uma nova concentração de cossubstrato.

\subsection{Etapa 2}

As características da água residuária antes e após o tratamento são apresentadas nas tabelas 3 e 4.

Tabela 3: Características da água residuária sintética que foi utilizada na alimentação do reator (Etapa 2)

\begin{tabular}{|c|c|}
\hline \multirow{2}{*}{ Variável } & $\begin{array}{c}\text { Concentração média / desvio padrão } \\
\text { Phanerochaete chrysosporium }\end{array}$ \\
\hline CORANTE & $20,43 \pm 0,71$ \\
\hline DQO BRUTA & $2124,72 \pm 961,15$ \\
\hline pH & $4,99 \pm 0,01$ \\
\hline
\end{tabular}

Tabela 4: Características da água residuária que saía do reator em 48horas (Etapa 2)

\begin{tabular}{|c|c|}
\hline \multirow{2}{*}{ Variável } & $\begin{array}{c}\text { Concentração média / desvio padrão } \\
\text { Phanerochaete chrysosporium }\end{array}$ \\
\cline { 2 - 2 } & $5,07 \pm 4,99$ \\
\hline CORANTE & $882,12 \pm 457,06$ \\
\hline DQO BRUTA & $2,96 \pm 0,25$ \\
\hline
\end{tabular}

Os dados obtidos para corante na etapa 2 foram superiores àqueles observados na etapa 1 (Figura 14). A eficiência média de remoção foi de $75 \%$, com máxima de $98 \%$ no ciclo 3 , e mínima de $34 \%$, no ciclo 7. A concentração máxima ocorreu no ciclo 7, de 13,15 mg. $\mathrm{L}^{-1}$, e a mínima ocorreu no ciclo 3 , de $4,3 \mathrm{mg} \cdot \mathrm{L}^{-1}$. 


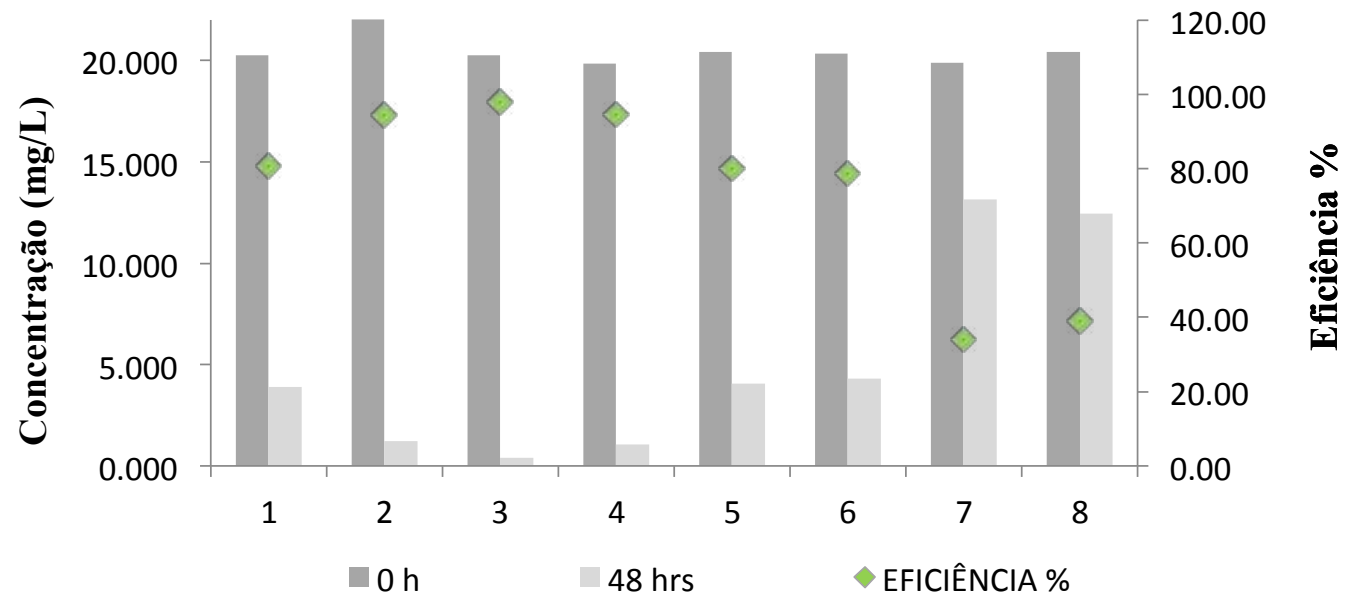

Figura 14 - Eficiência de Remoção de Corante em reator com inóculo de Phanerochaete chrysosporium (Etapa 2)

Em relação à matéria orgânica em termos de DQQ Bruta, a eficiência média foi de $60 \%$, com máxima de $76 \%$ no ciclo 5 e mínima de $43 \%$ no ciclo 4 (Figura 15). Ao contrário do que aconteceu na etapa 1, a eficiência de remoção de corante foi superior àquelas observadas para DQQ, indicando que talvez a operação em batelada escalonada não seja tão viável para esse tipo de tratamento.

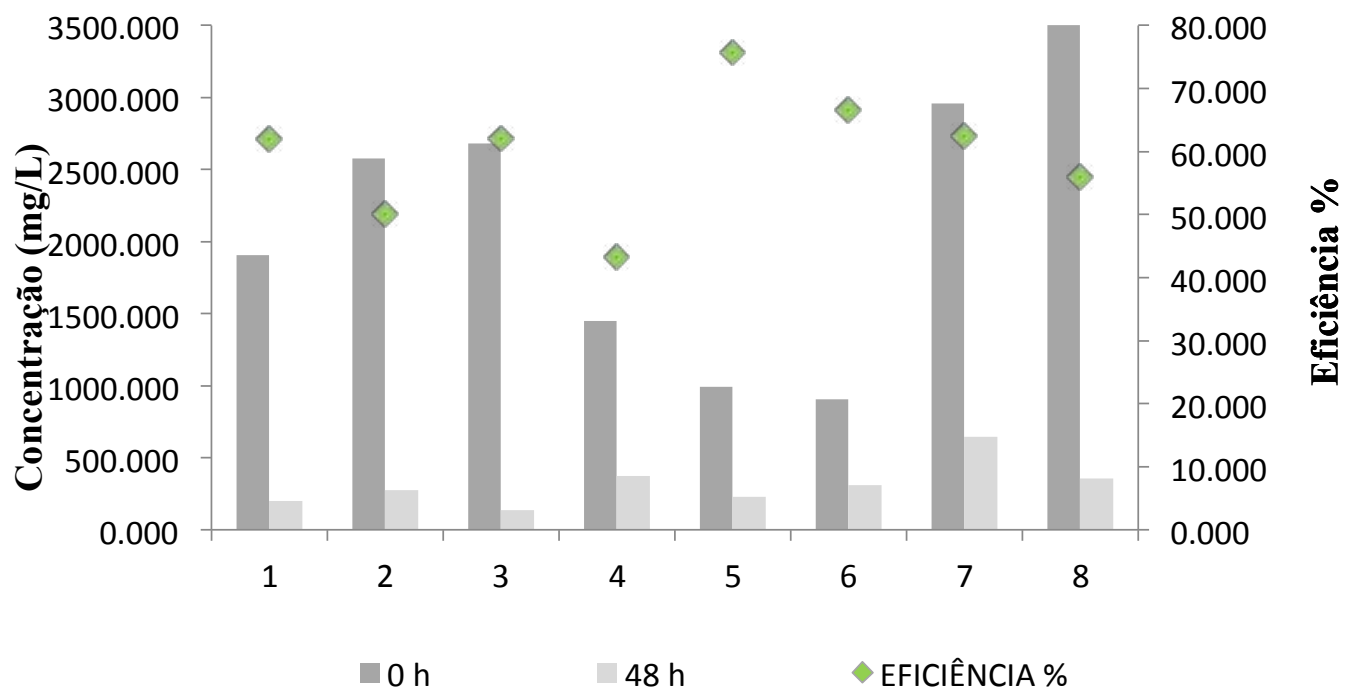

Figura 15 - Eficiência de Remoção de DQ̣O Bruta em reator com inóculo de Phanerochaete chrysosporium (Etapa 2).

Na etapa 2, os valores de pH se mantiveram na faixa ácida, em torno de 2,96, com máxima de 3,39 no ciclo 2 e mínima de 2,72 no ciclo 8 (Figura 16). 


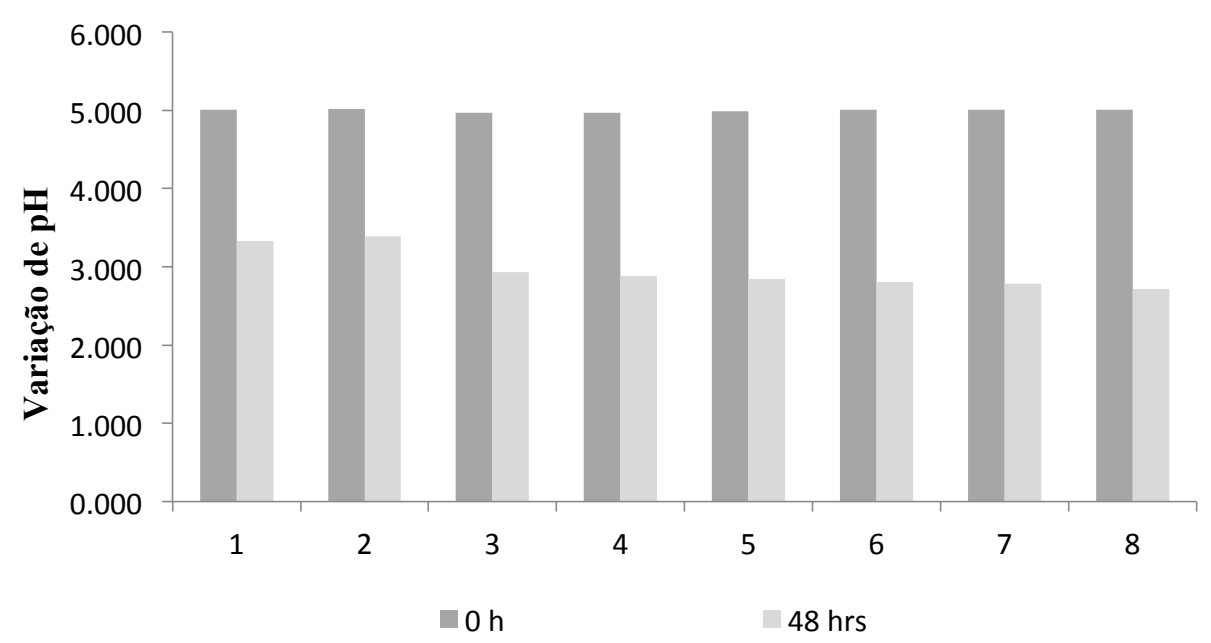

Figura 16 -Variação de pH em reator com inóculo de Phanerochaete chrysosporium (Etapa 2).

Segundo Mielgo et al (2001), os fungos de decomposição branca, como o Phanerochaete chrysosporium, são conhecidos por sua habilidade de produzir enzimas extracelulares oxidativas que iniciam um processo chamado de polimerização lignolítica, permitindo sua aplicação em uma série de processos biotecnológicos.

Li et al (2015) realizaram o estudo da degradação de índigo carmim por Phanerochaete chrysosporium em meio contendo resíduo de mandioca. Foram utilizados erlenmeyers contendo corante em concentração de $30 \mathrm{mg} \cdot \mathrm{L}^{-1}$ e uma solução de MnP (Manganês Peroxidase) Bruta, obtida por meio dos sobrenadantes das amostras. Os autores realizaram uma descoloração in vitro, em que se obteve uma remoção de $90,2 \%$ do corante em 6 horas de incubação.

Barreto et al (2011) estudaram a biodegradação de uma mistura de corantes têxteis usando o fungo Ganoderma sp, que assim como o Phanerochaete chrysosporium é um fungo de podridão branca. Os autores utilizaram três tipos de corante reativos, sendo eles o Azul Procion, o Amarelo Procion e o Vermelho Procion em uma concentração de 50 mg.L, onde foram adicionados em Erlenmeyers de 125 $\mathrm{mL}$ contendo água destilada, $3 \mathrm{~g}$ de sal refinado, 1 $\mathrm{g}$ de barrilha leve, $0,5 \mathrm{~mL}$ de meio Vogel e $0,05 \mathrm{~g}$ de extrato de levedura em cada frasco. Os Erlenmeyers foram agitados em uma incubadora rotatória a 180 rpm, onde permaneceram por 72 horas, sendo que a cada 12 horas uma alíquota era retirada. Segundo os autores, a degradação dos corantes foi significativa em $72 \mathrm{~h}$ de incubação a $28^{\circ} \mathrm{C}$, sendo $33,6 \%$ para o corante Amarelo Procion, 43,5\% para o Azul Procion, e $57,7 \%$ para o Vermelho Procion.

No presente trabalho, os resultados para remoção de corante foram superiores àqueles observados por Barreto et al (2011); apesar de as naturezas dos corantes serem diferentes, houve maior remoção do corante índigo em menor espaço de tempo, remoção esta que foi superior à dos corantes reativos, que ficaram mais tempo em contato com a biomassa do fungo Ganoderma sp. A Manganês peroxidase é uma enzima lignolítica produzida pelo fungo $P$. chrysosporium, que foi utilizada em maior concentração após a produção desta pelo fungo nos estudos de Li et al (2015), através de uma descoloração in vitro que se mostrou muito eficiente devido à maior concentração da enzima.

Os resultados obtidos na etapa 2 se mostraram melhores do que aqueles obtidos na etapa 1, tanto para corante como para matéria orgânica, mostrando que a operação em batelada escalonada não é viável e eficiente para esse tipo de processo, sendo então melhor utilizar somente a adição de cossubstrato na metade do tempo reacional. 


\section{CONCLUSÃO}

Os reatores operados em batelada escalonada com fungos (Etapa 1) apresentaram baixa eficiência na remoção do corante sintético, sendo que as remoções de DQQO foram superiores em ambos os reatores. Além disso, não houve a degradação total do índigo, e ocorreu a geração de subprodutos aromáticos, como o benzeno, como observado nas varreduras realizadas.

O reator da etapa 2, operado em regime de batelada sequencial convencional com inóculo de Phanerochaete chrysosporium, apresentou melhores remoções de corante e DQO em relação à etapa 1, mostrando que é mais viável trabalhar desta maneira. $O$ estudo mostrou a necessidade de dar continuidade à pesquisa, com a utilização de outras espécies fúngicas nas condições adotadas na etapa 2 , a fim de encontrar a melhor condição de tratamento do efluente.

\section{REFERÊNCIAS}

ALMEIDA, D.G; SILVA, M.G.C; MENDONÇA, R.C; MACIEL, C.C.S; GUSMÃO, N.B. Descoloração do corante Índigo Carmim e produção de Lacase por fungos filamentosos. Scientia Plena; Vol. 8, n 5, 2012.

APHA. Standard Methods for examination of Water and Wastewater American WalterWork Association, Walter Enviroment Federation, $20^{\circ}$ edição, 2005.

BARRETO, W.J; BERNARDINO, N.D; AFONSO, R. Biodegradação de uma mistura de corantes usando o fungo Ganodermasp: Um Estudo Cinético. Química Nova. Vol. 34, n. 4, p. 568-572, 2011.

BERTAZOLLI, R; PELEGRINI, R. Descoloração e degradação de poluentes orgânicos em soluções aquosas através de processo fotoeletroquímico. Química Nova, São Paulo, vol. 15, n. 3, p. 477-482, 2002.

CARVALHO, E.S. Reuso do Mesocarpo de Coco na remoção de contaminação derivados de Petróleo presentes em corpos d'água, utilizando sistema de adsorção em leito diferencial. (Trabalho de Conclusão de Curso em Química Industrial) Universidade Estadual da Paraíba, Campina Grande, 2014.

CONSELHO NACIONAL DO MEIO AMBIENTE - CONAMA. 2011. Resolução Conama no 430. Disponível em: www.mma.gov.br/conama Acesso em 08/05/2017.

COSTA, T.B. Desempenho de Reator em Batelada Sequencial (RBS) com enchimento escalonado no tratamento de Esgoto Sanitário Doméstico. (Dissertação em Engenharia Ambiental) - Centro Tecnológico da Universidade Federal de Santa Catarina, Florianopólis, 2005.
DULLIUS, C. H. Utilização de fungos para biodegradação de corantes têxteis sintéticos. Dissertação (Mestrado em desenvolvimento Regional), Universidade Santa Cruz do Sul, Santa Cruz do Sul, 2004.

ERDUNLU, N. Reuse of effluent water obtained in different textile finishing processes. Autex Research Journal. Vol. 12, Issue1, Pages 23-28, março 2012.

GUARATINI, C.C.I; ZANONI, M.V. Corantes Têxteis. Química Nova. V. 23, n. 1 p. 71-78, Fevereiro, 2000.

HART, E. Reciclagem de Água, um Programa Economicamente Viável e Tecnicamente Inovativo. Tecnologia Meio Ambiente. Química Têxtil, p.07-10, fevereiro de 1994.

HESSEL, C.; ALLEGRE, C.; MAISSEU, M.; CHARBIT, F.; MOULIN, P. Guidelines and legislation for dye house effluents. J. Environmental Management., v. 83, n. 2, p. 171-180, 2007.

KOPRIVANAC, N.; KUSIC, H. Hazardous organic pollutants in colored wastewaters. New York: New Science Publishers, 2008.

KUNZ, A; PERALTA-ZAMORA, P; MORAES, S.G; DURÁN, N. Novas Tendências no Tratamento de Efluentes Têxteis. Química Nova. vol. 25, n.1, pág 78-72, 2002.

LEITE, A.S; TRINDADE, N.B; ARAÚJO, M.C; BEZERRA, R.N; ROSA, J.M; COSTA, M. Custos Ecológicos e Sustentabilidade em Recursos Hídricos na Indústria Têxtil. Revista de Ciências Agrárias. Vol. 17, n. 26, p. 103-111, 2013.

LI, H; ZHANG, R; TANG, L; ZHANG, J; MAO, Z. Manganese peroxidase production from cassava residue by Phanerochaete chrysosporium in solid state fermetationand its decolorizationof índigo carmine. Chinese Journal of Chinese Engineering. Vol. 23, p. 223-227, 2015

MIELGO, I. et al. A packed-bed fungal bioreactor for the contínuos decolourisation of azo-dyes (Orange II). Journal of Biotechnology, v. 89 , p. 99-106,

OTTONI. C. A. Descoloração de corantes têxteis por fungos lignolíticos em condições de pH e salinidade elevada. Tese (de doutorado em Engenharia Química e Biológica) - Escola de Engenharia, Universidade do Minho, Braga, 51p., 2012.

RIBEIRO, J.P; ALEXANDRE, J.E.C; NETO, E.F.A; PARENTE, T.C; SILVA, G.R; SILVA, J.C; NASCIMENTO, R.F. Uso do processo de Eletrocoagulação/Flotação no Tratamento de Efluente de Pós-Tingimento de uma Indústria de Redes. In: XX Congresso Brasileiro de Engenharia Química. Florianópolis, 2014.

RODRIGUES, K; SILVA, K.M.L; SILVA, G.M.M; LIMA, P.C.C. Remoção de corantes por uso de Aspergillus niger AN400 em reator em bateladas sequencias. Química Nova. Vol. 34, nº 7, p. 1119-1123, 2011.

SILVA , K.M.L; WANDERLEY, C.L.P; MARINHO, G; OLIVEIRA, J.C; SANTOS, A.D.O; RODRIGUES, K. Influência do excesso de nitrogênio amoniacal no tratamento de efluente têxtil em reator de bateladas sequenciais com Aspergillusniger AN 400. Engenharia Sanitária e Ambiental,v.20, n.4, pág 635-643, outubro/dezembro, 2015. 